\title{
Caliber persistent artery in the facial structures: A case report with emphasis in the diagnostic value of ultrasonography and an analysis of previously reported cases
}

\author{
Jorge Pinares Toledo ${ }^{1,2 *}$, Roberto Marileo Zagal ${ }^{3}$, Loreto Bruce Castillo ${ }^{2}$ and Francisca Montoya Salvadores ${ }^{3}$ \\ ${ }^{1}$ Área de Radiología, Departamento de Patología y Medicina Oral, Facultad de Odontología, Universidad de Chile \\ ${ }^{2}$ Escuela de Odontología, Facultad de Medicina, Pontificia Universidad Católica de Chile, Campus San Joaquin, Avda. Vicuña Mackenna 4860, Macul, Santiago, Chile \\ ${ }^{3}$ Instituto de Neurocirugía Dr Alfonso Asenjo, Avda, José Manuel Infante 553, Providencia, Santiago, Chile
}

\begin{abstract}
Objectives: One case of caliber persistent artery is reported in a facial area where it has not been previously described in the literature. The importance of ultrasonography in the diagnostic confirmation of this entity is emphasized. An analysis of previously reported cases on oral and facial caliber persistent artery was also conducted.

Methods: A case of a patient with caliber persistent artery in the buccal region of the face, studied by ultrasonography is described. Also, a MEDLINE, EMBASE and SCOPUS search was conducted from 1973 to 2019 using the terms "caliber persistent artery", "vascular anomalies" "vascular lesions", also together with "oral" and "facial". A total of 34 articles have been reviewed.

Results: At the age of 62 years old, a male patient presented a pulsatile swelling in the left buccal region of the face. Gray-scale ultrasound evaluation showed a luminal structure in the subcutaneous tissue. The spectral Doppler mode showed a systolic diastolic waveform, determining its arterial nature. The reviewed literature reveals that up to date, there are 275 cases of caliber persistent artery published and 305 diagnosed lesions related to the oral and facial structures, with males and females being affected quite symmetrically. Almost all reported cases in the literature correspond to caliber persistent artery affecting the lips mucosa and just seven cases were related to other structures. The affectation was almost equal between upper and lower lip, being the former affected in $49.6 \%$ of the cases, meanwhile the latter in $50.4 \%$ of the cases published.
\end{abstract}

Conclusions: This is the first case reported of caliber persistent artery in the buccal region of the face, which is predominantly seen in the lips. Other few cases of oral and facial caliber persistent artery have been reported affecting the oral buccal vestibule, and also palate, nasal vestibule and eyelids. Ultrasonography should be considered as the imaging modality of choice for confirming its diagnosis instead of unnecessary surgical procedure and biopsy.

\section{Introduction}

Caliber persistent Artery (CPA) is a vascular anomaly historically known as Dieulafoy's lesion, which is defined by the presence of a histologically normal vessel but with abnormally large caliber, within the submucosal that fails to diminish in diameter as it approximates the mucosa $[1,2]$.

Although Dr M.T. Gallard published the first cases of CPA in 1884 [3, 4], it was more accurately characterized clinical, anatomopathological and physiologically 14 years later, under the name of exulceratio simplex by the French physician and surgeon Professor of Clinical Medicine at the famous Hôtel-Dieu, Georges-Paul Dieulafoy and attributed to him the term "Dieulafoy's lesion" after he presented some cases of fatal gastric haemorrhage in 1898, in the French Academy of Medicine [4-6].

The term "caliber - persistence" was used for first time by D. Voth [7] in 1962 and later by G. Krasznai and V. Szokoly [8] in 1968. Afterward, Mikó, et al. [9] in 1988 stated that the most appropriate term for this condition was "caliber persistent artery". Thereafter, the designation was accepted by most of the authors.

Since the first descriptions of this condition at the end of the XIX century, there had been many case reports and reviews worldwide, especially about stomach, which is according to the literature, the most common site involved $[10,11]$.
Duodenum is affected in approximately one third of the extragastric cases [11]. Other anatomic locations are esophagus [12], bronchial tubes [13,14], sciatic area [15], trachea [16], as well as the facial territory [17]. In the facial region, lips have been the first and by far the most frequently reported anatomic structure affected by this anomaly.

As it has been previously stated in the literature, the first description of this condition in lips was made by Howell and Freedman [17] in 1973, under the title "Prominent inferior labial artery". Mikó, et al. [18] in 1980 reported the three first cases of this condition in the lower lip of adults under the name of caliber persistent labial artery (CPLA), and all the subsequent studies and reports in the English language literature have used the term CPLA.

*Correspondence to: Jorge Pinares Toledo, Área de Radiología, Departamento de Patología y Medicina Oral, Facultad de Odontología, Universidad de Chile, Sergio Livingstone Polhammer 943, Independencia, Santiago, Chile, Tel: +56 9 62401137; E-mail: jpinares@odontologia.uchile.cl

Key words: caliber persistent artery, facial structures, ultrasonography

Received: April 06, 2020; Accepted: April 20, 2020; Published: April 23, 2020 
The reports published about other oral and facial structures affected by CPA are scarce and limited just to palate $[19,20]$, lower buccal mucosa sulcus [21], nose [22] and to eyelid [23].

Surgical procedures and biopsy are still considered the gold standard for its diagnosis at the oral and facial structures [24-26], although there is no evidence in the most of cases, of progression through time $[27,28]$ Also, in a number of cases there are not complications to justify its surgical excision for treatment purposes. These arguments mentioned above lead to the necessity of turning into non-invasive medical procedures in order to determine its definitive diagnosis. Growing evidence suggests that high-resolution ultrasonography (US) could be recommended as the first-line diagnostic modality of CPA at oral and facial superficial soft-tissue structures, especially for lips $[29,30]$ and in many cases as the sole diagnostic method, given its well-known advantages [31] and its high diagnostic performance.

On the other hand, some clinical aspects of oral and facial territory CPA lesions have not been analyzed in the light of the information available so far, alongside with its US differential diagnosis from other pulsatile vascular anomalies.

Therefore, the purpose of this communication is to report a case of CPA in a facial location not being described before, emphasizing the US key contribution in its diagnosis and drawing attention about the US underutilization as first line noninvasive diagnostic tool of oral and facial CPA. Some clinical details regarding this relatively common but not often reported vascular anomaly are discussed, considering the information available up to date.

\section{Case Report}

In 2015, a 62 year old male patient was referred for evaluation due to a soft pulsating and painless slight swelling, in the buccal region next to the oral commissure in the left side of the face. The patient had been aware of this swelling for about 1 year, looking for medical assistance. He did not have any relevant medical history, and he did not refer history of trauma or damaging in the site of the lesion and did not note changes in the size of the lesion over the time.

The clinical examination revealed a slightly raised nonulcerated nodule in the skin with noticeable pulse, sessile and with soft consistency. The site of the lesion and surrounding tissues were nonulcerated, without erythema and without color changes (Figure 1), remaining unchanged in the control of 2019.

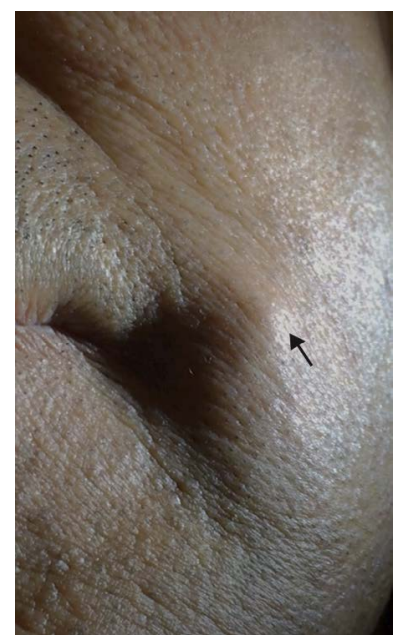

Figure 1. Clinical appearance of CPA in the buccal area of the left side of the face (arrow)
The patient underwent a high-resolution gray scale, pulsed and color Doppler US examination, carried out with a linear transducer with a frequency range $12-5 \mathrm{MHz}$, using a Philips IU22 ultrasound machine (Philips Medical Systems Inc, Bothell, Wash). The patient was placed sitting in a back-reclined position, performing the exam in longitudinal and transverse views to generate the best view of the lesion, determining the location and following the course of the vessel. Color Doppler images were obtained to assess blood flow and pulsed Doppler images to provide a flow waveform analysis of the lesion throughout the cardiac cycle. The contralateral side was also examined for comparison.

The gray scale US images showed a prominent luminal structure extending from the deep plane to reach the subcutaneous tissue with a pronounced abnormal curvature immediately under dermis layer (Figure $2 \mathrm{a}, \mathrm{b}$ ). It was of wide caliber, with $2 \mathrm{~mm}$ of maximum transversal diameter. The distance between the artery and the surface skin was 2.5 $\mathrm{mm}$. The peak systolic velocity was $33 \mathrm{~cm} / \mathrm{s}$ and end-diastolic velocity was $16 \mathrm{~cm} / \mathrm{s}$. The spectral curve analysis showed moderate flow velocity and low resistance flow (Figure $2 \mathrm{c}, \mathrm{d}$ ).

There was no evidence of arteriovenous shunts or abnormal vascular communication or calcific deposits. The structures surrounding the vessel appeared normal. The contralateral artery had normal appearance.

As it has been previously described, in this case the surgical intervention was not recommended because the patient was asymptomatic, without signs of complications and also because did not refer discomfort. However, the patient was well informed and warned about future possible complications.

\section{Discussion}

CPA was first described affecting the stomach submucosa [4]. However, regardless of the affected anatomic area, CPA is characterized for being a primary arterial branch with a large diameter, which passes through the muscle layer penetrating into the submucosal tissue to lie close to the mucosa surface, without reduction in its size.

A database MEDLINE, EMBASE and SCOPUS search was conducted on oral and facial structures CPA, using the terms "caliber persistent artery", "vascular anomalies", "vascular lesions" together with "oral" and "facial". Thirty-four articles between the years 1973 and 2019 were found (Table 1), with 275 cases published and 305 diagnosed lesions. Most of them correspond to case reports and just few to original researches, such as Lovas J, et al. [27] with 185 diagnosed individuals.

The majority of these published studies referred to CPA affecting the lips mucosa, except two cases involving the palate [19,20], one case in the lower buccal vestibule [21], another one compromising the nose [22] and three which were reported affecting eyelids [23]. Our case represents the first report in the literature in which CPA is localized elsewhere in the facial region.

The diagnosed patients reported in the literature were between 2 and 88 years of age, but most of the cases were found in individuals over 30 years old, which is consistent with the present case reported. Additionally, only three cases were under 22 years of age $(2,17$ and 20 years old respectively). However, it is important to mention that in one of the most extensive studies carried out about CPLA [27], the agerange of the studied sample is just mentioned, not being specific in the number of cases under 30 years of age.

On the other hand and considering all the studies published in which the gender of the diagnosed patients is specified, it is clearly 
Pinares J (2020) Caliber persistent artery in the facial structures: A case report with emphasis in the diagnostic value of ultrasonography and an analysis of previously reported cases

Table 1. Cases of oral and facial CPA reported in literature between 1973 and 2019

\begin{tabular}{|c|c|c|c|c|c|c|c|}
\hline \multicolumn{2}{|c|}{ Author } & \multirow{2}{*}{$\begin{array}{c}\text { Cases } \\
1\end{array}$} & \multirow{2}{*}{$\begin{array}{c}\text { Age (in years) } \\
51\end{array}$} & \multirow{2}{*}{$\begin{array}{c}\text { Gender } \\
\mathrm{F}\end{array}$} & \multirow{2}{*}{\begin{tabular}{|c|} 
Number of lesions \\
1
\end{tabular}} & \multirow{2}{*}{$\begin{array}{c}\text { Place } \\
\text { Upper lip }\end{array}$} & \multirow{2}{*}{$\begin{array}{c}\text { Diagnosis } \\
\text { Surgery - biopsy }\end{array}$} \\
\hline 1 & Spillinger, et al. (2019) [44] & & & & & & \\
\hline 2 & Thanthoni, et al. (2018) [30] & 1 & 24 & M & 1 & Upper lip & US \\
\hline 3 & Tobouti, et al. (2017) [45] & $*_{4}$ & 46 (medium age) & $\begin{array}{l}2 \mathrm{~F} \\
2 \mathrm{M}\end{array}$ & 4 & Lips & Biopsy - IHC \\
\hline 4 & Khalele, (2017) [20] & 1 & 66 & $\mathrm{~F}$ & 1 & Palate & Biopsy \\
\hline 5 & Agha-Hosseini, et al. (2016) [24] & 1 & 32 & M & 1 & Upper lip & Biopsy \\
\hline \multirow{5}{*}{6} & \multirow{5}{*}{ Awni, et al. (2016) [25] } & \multirow{5}{*}{5} & 29 & M & 1 & Lower lip & Biopsy \\
\hline & & & 75 & $\mathrm{~F}$ & 1 & Lower lip & Biopsy \\
\hline & & & 88 & M & 1 & Lower lip & Biopsy \\
\hline & & & 28 & $\mathrm{~F}$ & 1 & Lower lip & Biopsy \\
\hline & & & 56 & M & 1 & Lower lip & Biopsy \\
\hline 7 & Costa, et al. (2015) [38] & 1 & 58 & M & 1 & Lower lip & Surgery - biopsy \\
\hline 8 & Santagata, et al. (2015) [26] & 1 & 25 & $\mathrm{~F}$ & 1 & Upper lip & Biopsy - IHC \\
\hline 9 & Aga, et al. (2013) [41] & 1 & 62 & $\mathrm{~F}$ & 1 & Lower lip & Biopsy \\
\hline 10 & Arellano, et al. (2012) [53] & 1 & 2 & M & 1 & Upper lip & US \\
\hline 11 & Vazquez, et al. (2011) [54] & 1 & 52 & $\mathrm{~F}$ & 1 & Lower lip & US \\
\hline \multirow{4}{*}{12} & \multirow{4}{*}{ Wong, et al. (2011) [23] } & \multirow{4}{*}{3} & \multirow{2}{*}{58} & \multirow{2}{*}{$\mathrm{F}$} & \multirow{2}{*}{2} & Right lower eyelid & Biopsy \\
\hline & & & & & & Left lower eyelid & Biopsy \\
\hline & & & 34 & $\mathrm{~F}$ & 1 & Left upper eyelid & Biopsy \\
\hline & & & 44 & M & 1 & Left lower eyelid & Biopsy \\
\hline \multirow{5}{*}{13} & & & 82 & M & 1 & Lower lip & Biopsy \\
\hline & & & 35 & M & 1 & Lower lip & Biopsy \\
\hline & Rosdy, et al. (2010) [39] & 5 & 41 & $\mathrm{~F}$ & 1 & Lower lip & Biopsy \\
\hline & & & 40 & M & 1 & Lower lip & Biopsy \\
\hline & & & 61 & $\mathrm{~F}$ & 1 & Lower lip & Biopsy \\
\hline 14 & Piccione, et al. (2010) [37] & 1 & 40 & M & 1 & Lower lip & Biopsy \\
\hline 15 & Abdulhameed Abdulmajeed, et al. (2010) [21] & 1 & 54 & $\mathrm{~F}$ & 1 & Lower buccal vestibule & Biopsy \\
\hline 16 & Miah, et al. (2010) [22] & 1 & 55 & $\mathrm{~F}$ & 1 & Nasal vestibule & Biopsy \\
\hline 17 & Wortsman, et al. (2009) [40] & 1 & 65 & $\mathrm{~F}$ & 1 & Lower lip & US \\
\hline 18 & Kocyigit, et al. (2006) [36] & 1 & 20 & $\mathrm{~F}$ & 3 & $\begin{array}{c}\text { Left and right side lower lip/ } \\
\text { Upper lip }\end{array}$ & US \\
\hline & & & 52 & $\mathrm{~F}$ & 1 & Lower lip & US \\
\hline 19 & Vazquez, et al. (2005) [29] & 3 & 34 & $\mathrm{~F}$ & 1 & Lower lip & US - biopsy \\
\hline & & & 54 & $\mathrm{M}$ & 1 & Lower lip & Biopsy \\
\hline 20 & Lewis, et al. (2003) [28] & 1 & 60 & $\mathrm{~F}$ & 1 & Lower lip & Surgery \\
\hline 21 & Howell, et al. (2002) [35] & 28 & 35 and older & $\begin{array}{l}18 \mathrm{M} \\
10 \mathrm{~F}\end{array}$ & $\begin{array}{c}29 \text { (two lesions in } \\
\text { one person) }\end{array}$ & Lips & NI \\
\hline 22 & Martín, et al. (2002) [47] & 1 & 68 & $\mathrm{~F}$ & 1 & Lower lip & Surgery- biopsy \\
\hline & & & 36 & M & 1 & Lower lip & Biopsy \\
\hline 23 & Kua, et al. (2000) [48] & 3 & 35 & $\mathrm{~F}$ & 1 & Lower lip & Surgery- biopsy \\
\hline & & & 85 & M & 1 & Lower lip & Biopsy \\
\hline 24 & Flaitz, (2000) [32] & 1 & 45 & M & 1 & Upper lip & Clinical examination \\
\hline 25 & Martín-Dorado, et al. (2000) [46] & 1 & 58 & M & 1 & Lower lip & Biopsy \\
\hline 26 & Manganaro. 1998 [33] & 1 & 56 & $\mathrm{~F}$ & 2 & Upper lip & Bionsy \\
\hline 26 & Manganaro, 1998 [35] & 1 & 56 & $\mathrm{~F}$ & 2 & Lower lip & B1opsy \\
\hline & & 162 & 22 to 88 & $\begin{array}{l}86 \mathrm{~F} \\
76 \mathrm{M}\end{array}$ & 187 & $\begin{array}{l}110 \text { upper lip ( } 7 \text { bilateral)/ } \\
64 \text { lower lip ( } 6 \text { bilateral) }\end{array}$ & Clinical diagnosis \\
\hline 27 & Lovas, et al. (1998) [27] & "23 & 30 to 84 & $\begin{array}{l}13 \mathrm{~F} \\
9 \mathrm{M}\end{array}$ & 23 & $\begin{array}{l}17 \text { lower lip/ } \\
6 \text { upper lip }\end{array}$ & Biopsy \\
\hline 28 & Payement, et al. (1998) [49] & 1 & 17 & M & 1 & Lower lip & Surgery- biopsy \\
\hline & Jovas etal (1993) [501 & 2 & 46 & $\mathrm{~F}$ & 1 & Lower lip & Surgery \\
\hline 29 & Lovas, et al. (1993) [50] & 2 & 24 & $\mathrm{~F}$ & 1 & Lower lip & Angiogram- Surgery \\
\hline 30 & Jaspers, (1992) [19] & 2 & 69 & M & 1 & Palate & Biopsy \\
\hline 30 & Jaspers, (1992) [19] & 2 & 40 & M & 1 & Lower lip & Biopsy \\
\hline 31 & Marshall, et al. (1985) [42] & 1 & 72 & $\mathrm{~F}$ & 1 & Lower lip & Biopsy \\
\hline 32 & Mikó, et al. (1983) [43] & 1 & 66 & M & 1 & Lower lip & Biopsy \\
\hline & & & 88 & M & 1 & Lower lip & Biopsy \\
\hline 33 & Mikó, et al. (1980) [18] & 3 & 56 & M & 1 & Lower lip & Biopsy \\
\hline & & & 70 & M & 1 & Lower lip & Biopsy \\
\hline 34 & Howell, et al. (1973) [17] & 10 & Over 40 & NI & 1 per case & Lower lip & $\begin{array}{l}\text { In one case, the lesion was } \\
\text { excised for study }\end{array}$ \\
\hline
\end{tabular}

F, female; M, male; NI, not informed; IHC, immunohistochemical analysis; they correspond to histopathological cases, not patients. 

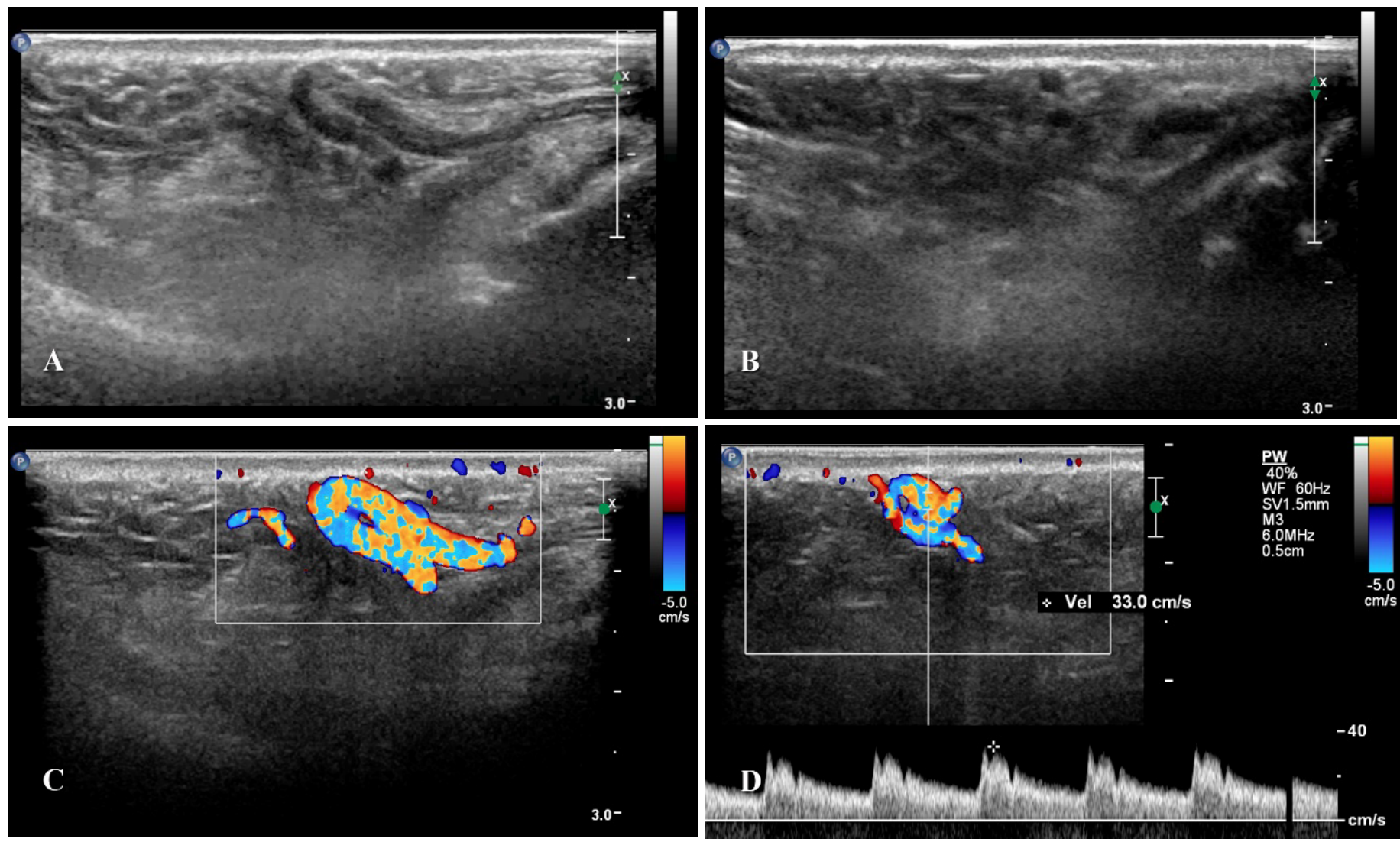

Figure 2. A, Longitudinal gray-scale sonogram showing luminal structure with notorious curvature in the subcutaneous fat layer of the buccal area of the face, immediately under the deep dermis. B, Transversal gray-scale sonogram view of the lesion. C, Longitudinal color Doppler scan showing a vessel with a turbulent blood flow instead of a laminar flow. D, Spectral Doppler US image shows a systolic - diastolic waveform, determining its arterial nature

observed that there is a similarity in the frequency between afflicted men and women, with a slight female predilection, which agrees on what has been pointed out by some authors [32]. According to the articles reviewed, the total number of women and men affected by this vascular anomaly was 135 and 129 respectively.

Also, based on the articles reviewed about CPA in oral and facial region that specify the frequency with upper and lower lip were affected, it was possible to determine that the number of cases was almost equal between both lips, with upper lip being affected in $49.6 \%$ of the cases published (124) versus lower lip with $50.4 \%$ of the cases (126). This contrasts with what has been stated by some authors who have mentioned that lower lip is most frequently affected [25,30,33], even stating that CPA occurs on the lower lip $80 \%$ of the time [34]. However, it is also important to consider that Howell $\mathrm{J}$ and Freeman $\mathrm{R}$ [35], did not specify in their work of 28 individuals, the distribution of the cases according to the affected lip.

This entity affecting oral and facial structures is in most of the cases visualized on physical examination as a solitary lesion. In the reviewed published cases, just 16 individuals presented two lesions [23,27,33,35] and only in one case was identified three lesions, located in lips [36]. Besides, CPLA is shown as a slightly elevated, soft lesion that can be ulcerated, bluish or with normal mucosal, either in linear, papular or nodular form, which represents a noticeable bend of the artery just below the epithelium. In our case, there was just one lesion in the oral and facial soft-tissue structures of the patient, identified by simple inspection as a slightly elevated round nodule with normal skin. This elevated nodule was representing the artery curvature in the subcutaneous tissue, just under the dermis. In the four year-control of this patient case, the lesion has not showed any increasing size. Additionally, Lovas J, et al. [27] did not encounter any history of progression of the lesions analyzed with age, as well as, the case reported by Piccione $\mathrm{M}$, et al. [37].

Different from many cases of CPA affecting lips which are usually asymptomatic and diagnosed during a routine clinical examination [38], in our described case, the patient was looking for specialized health care due to the presence of a small swelling associated to pulse. Then, from a clinical point of view, in this case the pulse was the dominant characteristic, which is in agreement with previous observations [32], which emphasize that the visible or palpable pulse could be the main particular feature that suggests the presence of this entity, being possible to establish its clinical diagnosis more easily, as it was stated by Santagata M, et al. [26]. However, it is important to consider that there are some other vascular lesions that clinically also show pulse. But undoubtedly, when the pulsation is not evident, the clinical diagnosis of oral and facial soft-tissue superficial structures CPA may be a challenge, because the number of possible conditions in its differential diagnosis increase [25,30,39-46].

Also, the clinical diagnosis of CPLA could be more difficult when it is located immediately subjacent to the mucosa, with even no sign of elevation [27] or be masked by any unrelated lesion, such as mucocoele or chronic ulcer. In these cases, its diagnosis could be easily missed.

Once the CPLA diagnosis has been made, treatment is generally not indicated $[27,28]$, except in cases of discomfort, cosmetic or functional impairment, bleeding, ulcer, injure or trauma [37,47-49]. On the other hand, a surgical procedure without awareness of CPLA 

reported cases

presence, could lead to an unexpected and profuse arterial bleeding [28]. Therefore, an early detection and diagnosis of CPLA should be made, using noninvasive methods, in order to be aware of its presence to avoid complications.

However, most of the CPA oral and facial cases published until now have been usually confirmed surgically and histologically. Sometimes it has also been used angiography [50] and even immunohistochemistry [26]. Them represent invasive diagnostic techniques, which in some cases are also intricate and expensive. Nevertheless, according to the CPA nature and its general long-term natural course, invasive techniques are not necessary. In instead, it is recommended a simple, safe and non-invasive diagnostic technique such as US.

Diagnostic US is a medical cross-sectional anatomic and flow image system based on the application of ultrasound [51], that considering its well-known advantages, constitute a valuable noninvasive cost effective diagnostic imaging technique in the examination of soft tissues at high spatial and contrast resolution, which allows a dynamic study, being the area under examination interrogated in real time, encompassing Doppler mode which includes the detection, quantization and evaluation of tissue motion and blood flow by using the Doppler effect [51]. Also, US is free of artifact like those of computed tomography metallic artifacts and magnetic susceptibility artifacts produced by some dental fillings, which is critical in order to obtain an appropriate representation of soft tissues close to metal filling teeth. Furthermore, the advances in US technology by which it has been possible to count on sophisticated machines with powerful processors that work with higher and variable frequency probes that also exhibit more convenient size and shape as hockey stick-shaped which adapts better to some different anatomical regions [52], have enlarged in the last decade the spectrum of US applications to intraoral and facial superficial soft tissues.

These attributes become US in a powerful diagnostic tool in the evaluation of orofacial soft tissue small lesions, establishing meaningful advantages over Multidetector Computed Tomography and Magnetic Resonance in a variety of clinical cases, being capable of providing unique diagnostic information, including oral and facial CPA. However, in spite of all the US advantages and as it is showed in Table 1, there are just few authors who have advocated its use for oral and facial CPA diagnosis $[29,30,36,40,53,54]$.

In the present case, it was clearly observed by B-mode ultrasound images with linear high-frequency transducer a prominent luminal structure with well definite margins, in superficial location, just below the dermis, to $2.5 \mathrm{~mm}$ from the epithelium surface, with a noticeable curvature, which was elevating the skin, explaining the clinical finding of nodule. Color-flow mode showed that this luminal structure was a vessel going through muscular layer, with a turbulent blood flow rather than a laminar flow. The spectral Doppler showed a systolic diastolic waveform of low resistance, determining its arterial nature. The opposite side of the region was clinically normal, and the corresponding normal artery was visible in a deeper layer. These characteristics are useful in distinguishing facial CPA from other vascular lesions that may present clinically as a pulsating swelling, such as small superficial arteriovenous fistula (AVF), true and false peripheral arterial aneurysm of the external carotid artery branches, and eventually also extracranial arteriovenous malformation (AVM). However, AVMs are congenital, often large, diffuse, cosmetically disfiguring and painful lesions, that have gradual progression in proportion to patient development [55]. Despite this, there could be variations in size and complexity of these lesions among different patients [56]. Some of them could be small, superficial and well-localized [57].
US is often used initially in superficial AVMs which are fast-flow anomalies consisting of multiple abnormal direct communications between arteries and veins due to absent normal capillary network $[58,59]$. Different from CPA, on US this entity is characterized by the presence of a conglomerate of tortuous vessels, showing Color Doppler examination high vascular density with multidirectional high flow. Spectral Doppler analysis shows high velocities, low resistance and spectral broadening in the arteries, which is more evident when compared with normal arteries in the adjacent soft tissues not involved by the malformation or in the contralateral side. Spectral Doppler analysis of the venous component shows pulsatile flow with relatively high velocities and arterial waveforms $[58,60]$.

Differently, AVF is a vascular lesion characterized by a single communication between the feeding artery and the draining vein through which blood bypasses the capillary network $[61,62]$. Both the feeding artery and the draining vein are typically grossly dilated and tortuous, resembling a varix [63]. Although its clinical presentation depends on the size, location and in its effect on local hemodynamics [64], it tends to present clinically as a pulsatile mass with a palpable thrill and a continuous bruit [63-65]. Unlike CPA, Color Doppler and duplex US of AVF show low and high resistance flow in the supplying artery, high-velocity arterialized waveform in the draining vein and turbulent high-velocity low spectrum at the junction of the artery and vein [66].

On the other hand, peripheral arterial aneurysm is an abnormal and localized enlargement of a blood vessel $[67,68]$. In the extracranial head and neck the external carotid, superficial temporal and facial arteries are the most frequently affected vessels [69-71]. The most common presentation of facial aneurysms is a soft, compressible and pulsatile mass [69,72]. Different from CPA, US gray-scale imaging reveal a focal dilated cavity and color Doppler images show turbulent arterial blood and trombothic masses inside [69].

\section{Conclusions}

This paper depicts one case of CPA in the face, close to the left angle of the mouth, where it has not been described before, emphasizing the valuable role of US in its diagnosis and also analyzing the previously reported cases on oral and facial caliber persistent artery.

Oral and facial CPA is found mostly in adults over 30 years of age, with quite equal distribution between men and women. Most of the cases of facial CPA described in literature affect lips, involving both upper and lower lip almost in identical proportion. Few cases are described affecting other oral and facial structures.

Clinically, one of the main particular features that could suggest the presence of this entity is the visibly or palpably pulse. Among the entities exhibiting pulse to consider in the differential diagnosis of oral and facial CPA are AVF and peripheral arterial aneurysm.

Oral and facial CPA lesions commonly do not require treatment, consequently its diagnosis as well as its management should be conservative, except in cases of surgical procedures involving the affected area, cosmetic impairment, bleeding or ulcer.

US is a powerful, cost-effective, safe and noninvasive medical imaging method that provides unique clinical information in the differential diagnosis of oral and facial soft-tissues CPA from other conditions, especially those that do not exhibit pulse. However, few authors have advocated the use of US to confirm the diagnosis of this disorder. US should be considered the first-choice modality for the 
Pinares J (2020) Caliber persistent artery in the facial structures: A case report with emphasis in the diagnostic value of ultrasonography and an analysis of previously reported cases

diagnosis and follow-up of oral and facial CPA, instead of unnecessary surgical procedure and biopsy.

\section{References}

1. Kanth R, Mali P, Roy PK (2015) Outcomes in Dieulafoy's lesion: A 10-year clinical review. Dig Dis Sci 60: 2097-2103.

2. Chaer RA, Helton WS (2003) Dieulafoy's disease. J Am Coll Surg 196: 290-296.

3. Gallard MT (1884) Anéurysmes miliaires de l'estomac, donnant lieu à des hématémèses mortelles. Bull Soc Med Hop Paris 1: 84-91.

4. Cadiot G (2008) L'exulceratio simplex de Dieulafoy. In: Vicari F, Papazian A. De Barrett à Zollinger-Ellison Quelques cas historiques en gastroentérologie. France, Paris: Springer p: 55-64.

5. Dieulafoy G (1898) Exulceratio simplex. L'intervention chirurgicale dans les hématémèses foudroyantes consécutives à l'exulcération simple de l'estomac. Bull Acad Med 49: 49-84.

6. Karamanou M, Fiska A, Demetriou T, Androutsos G (2011) Georges-Paul Dieulafoy (1839-1911) and the first description of "exulceratio simplex". Ann Gastroenterol 24: 188-191.

7. Voth D (1962) Das architektonische Prinzip der magearterien in seiner Bedeutung fur die Magenblutung. Zentralblatt fur Allgeemeine Pathologie und Pathologische Anatomie 103: 553-554.

8. Krasznai G, Szokoly V (1968) Congenital vascular malformation ("calibrepersistence") as a pathogenic factor of lethal gastric haemorrhage. Acta Chir Acad Sci Hung 9: 137-142.

9. Mikó TL, Thomázy VA (1988) The caliber persistent artery of the stomach: a unifying approach to gastric aneurysm, Dieulafoy's lesion and sub-mucosal arterial malformation. Hum Pathol 19: 914-921.

10. Schmulewitz N, Baillie J (2001) Dieulafoy lesions: a review of 6 years of experience at a tertiary referral center. Am J Gastroenterol 96: 1688-1694.

11. Baxter M, Aly EH (2010) Dieulafoy's lesion: current trends in diagnosis and management. Ann R Coll Surg Engl 92: 548-554.

12. Malliaras GP, Carollo A, Bogen G (2016) Esophageal Dieulafoy's lesion: an exceedingly rare cause of massive upper GI bleeding. J Surg Case Rep 6: rjw074.

13. Smith B, Hart D, Alam N (2014) Dieulafoy's disease of the bronchus: a rare cause of massive hemoptysis. Respirol Case Rep 2: 55-56.

14. Kuzucu A, Gürses I, Soysal O, Kutlu R, Ozgel M (2005) Dieulafoy's disease: a cause of massive hemoptysis that is probably underdiagnosed. Ann Thorac Surg 80: 1126-1128.

15. Futamata H, Kawate T, Sakamoto H, Kitami Y, Takeda S (2008) Large-caliber persistent sciatic artery with aneurysm. Anat Sci Int 83: 301-306.

16. Yang D, Rong C, Gu J, Xu L, Zhang J, et al. (2017) Dieulafoy disease of the trachea with recurrent episodes of massive hemoptysis: A case report. Medicine 96: e5855.

17. Howell JB, Freeman RG (1973) Prominent inferior labial artery. Arch Dermatol 107: 386-387.

18. Mikó T, Adler P, Endes P (1980) Simulated cancer of the lower lip attributed to a "caliber persistent" artery. J Oral Pathol 9: 137-144.

19. Jaspers MT (1992) Oral caliber-persistent artery. Unusual presentations of unusual lesions. Oral Surg Oral Med Oral Pathol 74: 631-633.

20. Khalele BAO (2017) Caliber persistent artery in the palate of an Egyptian patient with type 2 diabetes mellitus: a rare case report. Pathologica 109:148-150.

21. Abdulhameed Abdulmajeed A, Farah CS (2010) Intra-oral calibre persistent artery. $J$ Craniomaxillofac Surg 38: 331-333.

22. Miah MS, White SJ, Mahendran S (2010) Calibre-persistent artery of the nose. $J$ Otolaryngol Head Neck Surg 39: E74-E77.

23. Wong KK, Roberts F, Cauchi P, Diaper C (2011) Caliber persistent artery of the eyelid. Graefes Arch Clin Exp Ophthalmol 249: 1395-1397.

24. Agha-Hosseini F, Sheykhbahaei N (2016) A new approach to the management of caliber-persistent artery: A case report and analysis of previously reported cases. Int J Dermatol 55: 11-16.

25. Awni S, Conn B (2016) Caliber-persistent labial artery: A rarely recognized cause of a lower lip swelling-report of 5 cases and review of the literature. J Oral Maxillofac Surg 74: 1391-1395.
26. Santagata M, Maglione M, Colella G, D'Amato S (2015) Calibre persistent labial artery: Clinical features and immunohistochemistry diagnosis. J Maxillofac Oral Surg 14: $845-847$.

27. Lovas JG, Rodu B, Hammond HL, Allen CM, Wysocki GP (1998) Caliber-persistent labial artery. A common vascular anomaly. Oral Surg Oral Med Oral Pathol Oral Radiol Endod 86: 308-312.

28. Lewis DM (2003) Caliber-persistent labial artery. J Okla Dent Assoc 93: 37-39.

29. Vazquez L, Lombardi T, Guinand-Mkinsi H, Samson J (2005) Ultrasonography: A noninvasive tool to diagnose a caliber-persistent labial artery, an enlarged artery of the lip. J Ultrasound Med 24: 1295-1301.

30. Thanthoni M, Rajeev P, Sathasivasubramanian S (2018) Caliber-persistent labia artery: A report of a rarely recognized lip swelling. J Clin Imaging Sci 8: 41.

31. Lieu D (2010) Ultrasound physics and instrumentation for pathologists. Arch Pathol Lab Med 134: 1541-1556.

32. Flaitz CM (2000) Caliber-persistent labial artery of the maxillary lip. Am J Dent 13: 107-108.

33. Manganaro AM (1998) Caliber-persistent artery of the lip: case report. J Oral Maxillofac Surg 56: 895-897.

34. Greenberg SA, Schlosser BJ, Mirowski GW (2017) Diseases of the lips. Clin Dermatol 35: e1-e14.

35. Howell JB, Freeman RG (2002) The potential peril from caliber-persistent arteries of the lips. J Am Acad Dermatol 46: 256-259.

36. Kocyigit P, Kocyigit D, Akay BN, Ustuner E, Kisnisci R (2006) Calibre persistent labial artery: clinical features and noninvasive radiological diagnosis. Clin Exp Dermatol 31: 528-530.

37. Piccione MJ, Manganaro AM, Almony JS (2010) Caliber-persistent labial artery: diagnosis and treatment - case report. J Oral Maxillofac Surg 68: 1987-1989.

38. Costa SA, Ruiz MM, Kaba SP, Florezi GP, Lemos Júnior CA, et al. (2015) Caliberpersistent artery. Case Rep Dent 2015: 747428.

39. Rosdy NM, Firth NA, Rich AM (2010) Calibre-persistent labial artery: often misdiagnosed as a mucocoele. Int J Oral Maxillofac Surg 39: 1230-1233.

40. Wortsman X, Calderón P, Arellano J, Orellana Y (2009) High-resolution color Doppler ultrasound of a caliber-persistent artery of the lip, a simulator variant of dermatologic disease: case report and sonographic findings. Int J Dermatology 48: 830-833.

41. Aga F, Mukhtar Z, Hardee P (2013) A rare case of calibre persistent labial artery presenting as a mucocoele. Oral Surg 6: 159-160.

42. Marshall RJ, Leppard BJ (1985) Ulceration of the lip associated with a calibrepersistent artery. BrJ Dermatol 113: 757-760.

43. Mikó TL, Molnár P, Vereckei L (1983) Interrelationships of calibre persistent artery, chronic ulcer and squamous cancer of the lower lip. Histopathology 7: 595-599.

44. Spillinger A, Gutierrez CN, Tillman EA, Rivera M, Van Abel KM (2019) A report of a caliber-persistent labial artery accompanied by uncharacteristic symptomology. $J$ Stomatol Oral Maxillofac Surg S2468-7855: 30251-30254.

45. Tobouti PL, Olegário I, de Sousa SC (2017) Benign vascular lesions of the lips: Diagnostic approach. J Cutan Pathol 44: 451-455.

46. Martín-Dorado M, Sánchez E, Casellas M, Marinero S, Cuerda E (2000) Arteria de calibre persistente del labio. Actas Dermosifiliogr 91: 457-459.

47. Martín JM, Pinazo MI, Montesinos E, Monteagudo C, Jordá E (2002) Labial erosion associated with a caliber-persistent artery. Med Cutan Ibero Lat Am 30: 234-236.

48. Kua H, Blessing K, Holmes J, Burrell M (2000) Calibre persistent artery of the lip: an underdiagnosed entity? J Clin Pathol 53: 885.

49. Payement G, Combemale P, Richard L, Tavera E (1998) Chronic lip ulcer. Apropos of a case of a superficial large diameter artery of the lower lip. Rev Stomatol Chir Maxillofac 98: 378-381.

50. Lovas JG, Goodday RH (1993) Clinical diagnosis of caliber-persistent labial artery of the lower lip. Oral Surg Oral Med Oral Pathol 76: 480-483.

51. Kremkau FW, Forsberg F (2010) Sonography principles and instruments. 8th ed. St Louis, Mo: Elsevier Saunders.

52. Wortsman X (2013) Ultrasound in dermatology: why, how, and when? Semin Ultrasound CT MR 34: 177-195. 
53. Arellano J, Antoniazzi C, Wortsman X (2012) Early diagnosis of a calibre persistent labial artery in a child: usefulness of ultrasonography. Australas J Dermatol 53: e18-e19.

54. Vazquez L, Carrel JP, Samson J (2011) Artère labiale de calibre persistant. Med Buccale Chir Buccale 17: 171-172.

55. Qiao C, Richter GT, Pan W, Jin Y, Lin X (2019) Extracranial arteriovenous malformations: from bedside to bench. Mutagenesis 34: 299-306.

56. Pedreira R, Lopez J, Ostrander B, Pearl M, Puttgen K, et al. (2019) An interdisciplinary approach to treatment of adult facial arteriovenous malformations: A review of the literature and a single institution's experience with "late" surgical resection and aesthetic reconstruction. J Craniofac Surg 30: 1635-1639.

57. Hua C, Yang X, Jin Y, Zou Y, Chen H, et al. (2018) Treatment of head and neck arteriovenous malformations involving the facial nerve: A tailored algorithm. Ann Plast Surg 81: S44-S53.

58. Paltiel HJ, Burrows PE, Kozakewich HP, Zurakowski D, Mulliken JB (2000) Softtissue vascular anomalies: utility of US for diagnosis. Radiology 214: 747-754.

59. Fevurly RD, Fishman SJ (2012) Vascular anomalies in pediatrics. Surg Clin North Am 92: 769-800.

60. Johnson CM, Navarro OM (2017) Clinical and sonographic features of pediatric softtissue vascular anomalies part 2: vascular malformations. Pediatr Radiol 47: 11961208 .

61. Trout HH 3rd, Tievsky AL, Rieth KG, Druy EM, Giordano JM (1987) Arteriovenous fistula simulating arteriovenous malformation. Otolaryngol Head Neck Surg 97: 322325 .
62. Wang C, Ge Y, Li L (2016) Traumatic arteriovenous fistula of the left parotid region: A case report. Oncol Lett 11: 3194-3196.

63. Yang M, Pan L, Cai MJ, Ma LT, Xu GZ, et al. (2014) Spontaneous arteriovenous fistula of the superficial temporal artery: Diagnosis and treatment. Clin Neurol Neurosurg 123: $18-24$.

64. Rance BR, Laws RA, Keeling 3rd JH, Warden PJ (1998) Traumatic arteriovenous fistula of the upper lip. Cutis 62: 235-237.

65. Toros S, Zorlu A, Deveci I, Deveci H, Naiboglu B, et al. (2010) Traumatic arteriovenous fistula of the upper lip: A case report. J Craniomaxillofac Surg 38: 485-487.

66. González SB, Busquets JC, Figueiras RG, Martín CV, Pose CS, et al. (2009) Imaging arteriovenous fistulas. Am J Roentgenol 193: 1425-1433.

67. Aggarwal S, Qamar A, Sharma V, Sharma A (2011) Abdominal aortic aneurysm: A comprehensive review. Exp Clin Cardiol 16: 11-15.

68. Hampel H, Villanueva J, Encina S (2001) True aneurysm of the facial artery. Report of a clinical case. Med Oral 6: 148-150.

69. Hoshi E, Owaki S, Ogawa F, Fukui J, Ogawa T, et al. (2010) True aneurysm of the facial artery. Auris Nasus Larynx 37: 656-658.

70. do Carmo Galindo C, Augusto Lima C, Galindo Filho G, Marcondes Penha F, do Carmo Galindo C (2006) True atherosclerotic aneurysm of the facial artery. Int J Oral Maxillofac Surg 35: 566-568.

71. Orihovac Z, Virag M, Manojlović S (1999) Traumatic facial artery aneurysm: case report. J Oral Maxillofac Surg 57: 199-201.

72. Kiernan A, Kinsella J, Tierney S (2018) Excision of true facial artery aneurysm using facial nerve monitoring. J Vasc Surg Cases Innov Tech 4: 126-127.

Copyright: (C)2020 Pinares J. This is an open-access article distributed under the terms of the Creative Commons Attribution License, which permits unrestricted use, distribution, and reproduction in any medium, provided the original author and source are credited. 